\title{
An in Vitro Study Elucidating the Effect of Oxidative Stress on Melanocytes
}

\author{
Mohmmad Shoab Mansuri ${ }^{1}$, Mala Singh², Shahnawaz D. Jadeja ${ }^{3}$, \\ Rasheedunnisa Begum ${ }^{4}$ \\ ${ }^{1,2,3,4}$ Department of Biochemistry, Faculty of Science, The Maharaja Sayajirao University of Baroda, \\ Vadodara-390002, Gujarat, India. \\ Corresponding Author: Rasheedunnisa Begum
}

\begin{abstract}
Oxidative stress plays a major role in melanocyte destruction in vitiligo; however the exact mechanism responsible for melanocyte death remains uncertain. We aimed to examine the effect of oxidative stress on melanocyte viability by MTT assay and expression of antioxidant genes (CAT, GPX1, G6PD and $P R D X 3)$, stress related genes (HSP60, HSP70, SERPI, SIRT1 and POLH) and melanocyte specific genes (MITF, TYR, TYRPl, TRPMI, $E D N 1, E Z R$ and $L A M P I)$ by real-time PCR upon exposing the normal human melanocytes (NHM), immortalized melanocytes derived from healthy human (PIG1) and from vitiligo patient (PIG3V) to cumene hydroperoxide (CHP). The transcript levels of selected genes were estimated by using real-time PCR. The NHM, PIG1 and PIG3V melanocytes showed significant decrease in viability under CHP (10$100 \mu \mathrm{M})$ induced oxidative stress. PIG3V displayed significantly increased expression of PRDX3, HSP70, SERP1, POLH as well as decreased expression of CAT, MITF, TYR, TYRP1, TRPM1, EDN1 and LAMP1 under CHP $(10 \& 20 \mu \mathrm{M})$ treatment, as compared to NHM and/or PIG1 melanocytes. These results suggest that vitiligo melanocytes are more sensitive to CHP induced oxidative stress, as compared to normal melanocytes. The present study demonstrates that vitiligo may result from an insufficient response of melanocytes to oxidative stress induced by high $\mathrm{H}_{2} \mathrm{O}_{2}$ levels.
\end{abstract}

Key words: Vitiligo; melanocyte; PIG1; PIG3V; oxidative stress; cumene hydroperoxide (CHP).

\section{INTRODUCTION}

The skin consists of the epidermis, the dermis, and a basement membrane which contains melanocytes originating from neural crest cells (Fuchs and Raghavan 2002; Proksch et al. 2008). Melanocytes, because of their vicinity, are liable to be attacked by several of exogenous chemicals (Bickers and Athar 2006). These environmental toxicants or their metabolites may produce various reactive oxygen species (ROS), such as hydrogen peroxide $\left(\mathrm{H}_{2} \mathrm{O}_{2}\right)$ (Bogeski et al. 2012). Uncontrolled release of ROS drives the induction of oxidative stress that can cause the destruction of melanocytes leading to vitiligo (Briganti and Picardo 2003; Spritz 2008). The presence of oxidative stress in both skin and blood of vitiligo patients has been well established (Beazley et al. 1999; Schallreuter et al. 1999). $\mathrm{H}_{2} \mathrm{O}_{2}$ amasses in the epidermis of patients, concomitant with reduced levels of catalase (Schallreuter $e t$ al. 1999). Altered antioxidant levels, including catalase (CAT), reduced glutathione (GSH), glutathione peroxidase (GPX), glucose 6-phosphate dehydrogenase (G6PD) and superoxide dismutase (SOD), and lipid peroxidation (LPO), was seen in vitiligo patients (Passi et al. 1998; Agrawal et al. 2004; Koca et al. 2004; Shajil and Begum 2006; Em et al. 2007; Laddha et al. 2013, 2014; Mansuri et al. 2016a) resulting into oxidative damage to melanocytes. These conditions may induce expression of stress proteins including heat shock protein 
70 (HSP70) and will enhance the activity of anti-oxidant enzymes to protect the cell (Calabrese et al. 2001; Renis et al. 2003).

Elevated $\mathrm{H}_{2} \mathrm{O}_{2}$ levels can alter calcium homeostasis (Schallreuter et al. 2007). The transient receptor potential cation channel, subfamily $\mathrm{M}$, member 1 (TRPM1) is a constitutively active $\mathrm{Ca}^{2+}$ channel, which is expressed in melanocytes and its activity is critical for melanocyte homeostasis(Hunter et al. 1998; Gaur et al. 2007; Devi et al. 2009). Moreover, it has been stated that the TRPMI expression is microphthalmia-associated transcription factor (MITF) reliant, which is considered as a key melanocyte regulator, controlling the expression of genes involved in melanogenesis including tyrosinase (TYR) and tyrosinase-related protein 1 (TYRP1) (Fang and Setaluri 1999; Widlund and Fisher 2003; Levy et al. 2010). The expression of MITF leads to a reduced oxidative stress response, suggesting its role in melanocyte stress response mechanism (Jiménez-Cervantes et al. 2001). However, the mechanisms underlying the aberrant responses induced by ROS-mediated melanocyte loss are not completely understood. Hence, we aimed to evaluate melanocyte viability, and to investigate the transcript expression levels of anti-oxidant genes (CAT, GPX1, G6PD and PRDX3), stress related genes (HSP60, HSP70, SERP1, SIRT1 and POLH) and melanocyte specific genes (MITF, TYR, TYRPl, TRPM1, EDN1 and LAMP1) in NHM, PIG1 and PIG3V cells under CHP induced oxidative stress.

\section{MATERIALS AND METHODS}

\subsection{Ethics statement}

The scheme of the present study was permitted by Institutional Ethics Committee for Human Research (IECHR) of Faculty of Science, The Maharaja Sayajjirao University of Baroda, Vadodara, Gujarat, India. The importance of the study was explained to all the participants for collecting the skin biopsies for NHM and written consent was obtained.

\subsection{Culture establishment of primary normal human melanocytes (NHM)}

Melanocytes were isolated from human skin biopsy samples and cultured successfully using the standard protocol with slight modifications (Im et al. 1993; Czajkowski et al. 2007). Melanocytes were used for experiments in the fifth or sixth passage.

\subsection{Human Melanocyte Cell lines}

Immortalized human melanocyte cell lines PIG1 (derived from healthy individual) and PIG3V (derived from vitiligo patient) were received from Dr. I.C. Le Poole, Loyola University, Chicago, Illinois and cultured as described by Le Poole (Le Poole and Boissy 1997; Le Poole et al. 2000).

\subsection{MTT assay}

The cell viability was monitored using MTT [3-(4,5-dimethylthiazol-2-yl)2,5- diphenyl tetrazolium salts]. NHM/ PIG1/ PIG3V cells were seeded in 96-well plate at a density of about 5000 cells in each well. Cells were treated with cumene hydroperoxide (CHP) (Sigma Aldrich, USA) in a dose dependent manner $(10,20$, $40,60,80 \& 100 \mu \mathrm{M})$. After $24 \mathrm{hrs}$ of treatment, MTT Assay (Molecular probes ${ }^{\circledR}$ by Life Technologies ${ }^{\mathrm{TM}}$, China) was performed as per the manufacturer's instructions.

\subsection{RNA isolation and cDNA synthesis}

\section{Total RNA from NHM/ PIG1/} PIG3V cells was extracted using RNA isolation kit (Ambion ${ }^{\circledR}$, Carlsbad, CA, USA) following the manufacturer's instructions. cDNA synthesis was performed using Verso cDNA Kit (Thermo Fisher Scientific Inc., USA) according to the manufacturer's instructions in the Mastercycler Gradient PCR (Eppendorf, Germany).

\subsection{Gene expression analysis}

The transcript levels of anti-oxidant, stress related and melanocyte specific genes in CHP treated and untreated cells were 
estimated by real-time PCR using SYBR green method and gene specific primers (Eurofins, Bangalore, India) as shown in Table S1. GAPDH was considered as a housekeeping gene. Real-time PCR was performed in duplicate using
LightCycler@480 SYBR Green I Master following the manufacturer's instructions and carried out in the Light Cycler 480 Real-Time PCR (Roche Diagnostics GmbH, Mannheim, Germany).

Table S1. Details of primers used for mRNA expression of the candidate genes.

\begin{tabular}{|c|c|c|c|c|}
\hline Gene & Forward/ reverse primer & Primer Sequence (5' to 3') & $\begin{array}{c}\text { Annealing } \\
\text { Temperature }\left({ }^{\circ} \mathbf{C}\right) \\
\end{array}$ & Amplicon size (bp) \\
\hline \multirow[t]{2}{*}{ EDN1 } & FP & ACTTCTGCCACCTGGACATCA & 63 & 91 \\
\hline & $\mathrm{RP}$ & TCCAAGGCTCTCTTGGACCTAG & & \\
\hline \multirow[t]{2}{*}{$E Z R$} & FP & TCCCTC AAAGAG TGATGG ACCAG & 65 & 100 \\
\hline & $\mathrm{RP}$ & TTA TCT TTG AGC ATC CCA CGG TG & & \\
\hline \multirow[t]{2}{*}{ LAMP1 } & FP & GCGAGCTCCAAAGAAATCAA & 63 & 95 \\
\hline & $\mathrm{RP}$ & TGGACCTGGGTGCCACTAA & & \\
\hline \multirow[t]{2}{*}{ POLH } & FP & ATCATGGAAGGGTGGTGGAAT & 63 & 167 \\
\hline & RP & TGGCTTCCCGGTACTTGG & & \\
\hline \multirow[t]{2}{*}{ SIRT1 } & FP & ACG CTG GAA CAG GTT GCG G & 64 & 168 \\
\hline & $\mathrm{RP}$ & AAG CGG TTC ATC AGC TGG GC & & \\
\hline \multirow[t]{2}{*}{ SERP1 } & FP & TCGCCAAGACCTCGAGAAATG & 62 & 101 \\
\hline & $\mathrm{RP}$ & CTGGAAAATTGCAGAACCACAGAC & & \\
\hline \multirow[t]{2}{*}{ TYR } & FP & AGCACCCCACAAATCCTAACTTAC & 63 & 92 \\
\hline & RP & ATGGCTGTTGTACTCCTCCAATC & & \\
\hline \multirow[t]{2}{*}{ TRPM1 } & FP & ACTCTAACAGGTGTTGCTGTGG & 62 & 153 \\
\hline & RP & CTGTTGGGTAGCTCTGGGTG & & \\
\hline \multirow[t]{2}{*}{ HSP60 } & FP & CTGGTGGTGCAGTGTTTGG & 62 & 269 \\
\hline & $\mathrm{RP}$ & TGTCCCACCAACCTTCAGC & & \\
\hline \multirow[t]{2}{*}{ HSP70 } & FP & TGAAGAAGGGTCAAGTGACTGTG & 62 & 162 \\
\hline & $\mathrm{RP}$ & ACTGAAAACTGAGCTATAGCAGG & & \\
\hline \multirow[t]{2}{*}{$P R D X 3$} & FP & TTCAGCACCAGTTCCTCATG & 60 & 168 \\
\hline & RP & AGGACACACAAAGGTGAAATCC & & \\
\hline \multirow[t]{2}{*}{ TYRP1 } & FP & TTT GTA ACA GCA CCG AGG ATG & 62 & 192 \\
\hline & RP & TGG GGT CAC TGT AAC CTT CCA C & & \\
\hline \multirow[t]{2}{*}{$G 6 P D$} & FP & TGAGCCAGATAGGCTGGAA & 63 & 225 \\
\hline & $\mathrm{RP}$ & TAACGCAGGCGATGTTGTC & & \\
\hline \multirow[t]{2}{*}{ MITF } & FP & CAAATGATCCAGACATGCGCTGG & 61 & 180 \\
\hline & $\mathrm{RP}$ & CTCGAGCCTGCATTTCAAGTTCC & & \\
\hline \multirow[t]{2}{*}{$C A T$} & FP & TAAGACTGACCAGGGCATC & 63 & 201 \\
\hline & $\mathrm{RP}$ & CAAACCTTGGTGAGATCGAA & & \\
\hline \multirow[t]{2}{*}{ GPX1 } & FP & GTTTGGGCATCAGGAGAACGCC & 64 & 147 \\
\hline & $\mathrm{RP}$ & AGGAAGGCGAAGAGAGGGTGC & & \\
\hline \multirow[t]{2}{*}{ GAPDH } & FP & ATCCCATCACCATCTTCCAGGA & 65 & 122 \\
\hline & RP & CAAATGAGCCCCAGCCTTCT & & \\
\hline
\end{tabular}

\subsection{Statistical analysis}

All the experiments were performed at least three times in triplicates independently on different days using different batches of cells, and data are presented as the mean \pm SEM. To evaluate the MTT or gene expression results, the absorbance or $\Delta \mathrm{Ct}$ values respectively, were compared between different groups and analysis was plotted and analyzed by nonparametric unpaired t-test using Prism 4 software (Graph Pad Software, USA, 2003) to determine the statistical significance of data. $p<0.05$ was considered statistically significant. Fold change in mRNA was calculated according to $2^{-\Delta \Delta \mathrm{Ct}}$ method.

\section{RESULTS}

\subsection{Dose dependent effect of CHP on melanocyte viability}




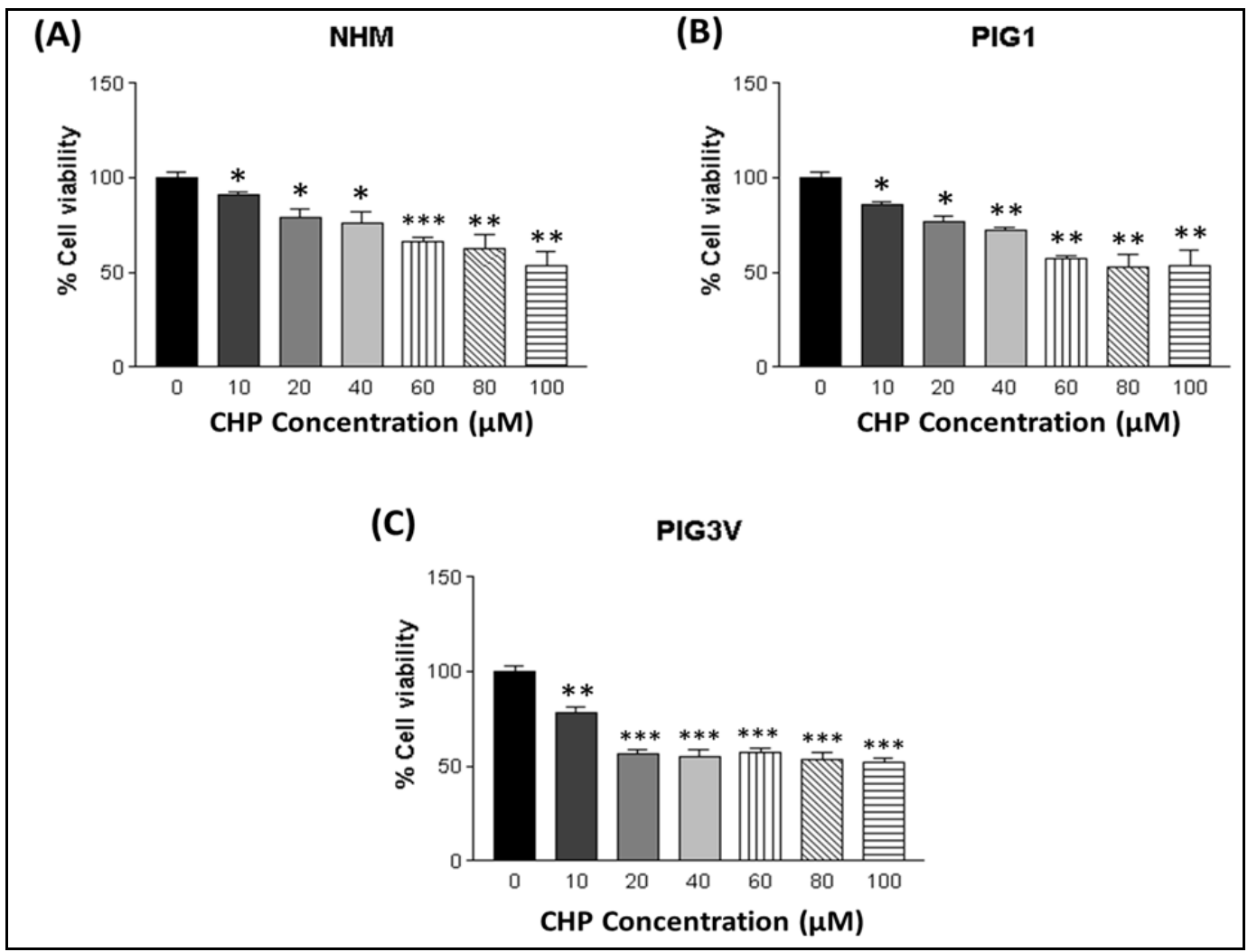

Figure 1. Dose dependent effect of CHP on melanocyte viability: (A) NHM, (B) PIG1 and (C) PIG3V cells showed significantly decreased viability upon 10, 20, 40, 60, 80 and $100 \mu \mathrm{M} \mathrm{CHP}$ treatments for $24 \mathrm{hrs}$ as compared to untreated cells $(\mathrm{n}=3)$.

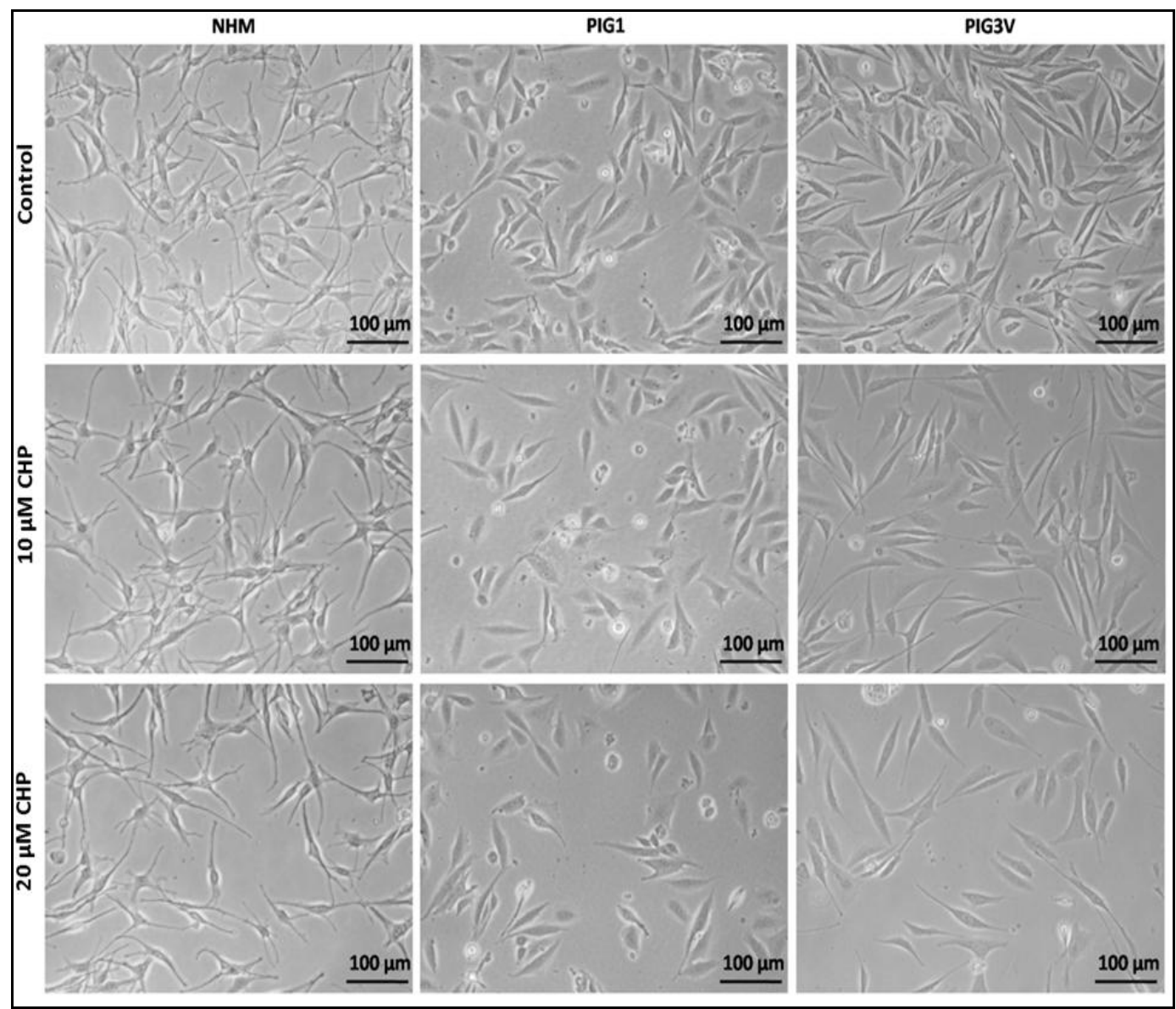

Figure 2. Effect of CHP on melanocytes: NHM, PIG1 and PIG3V cells showed significant decrease in viability upon 10 and $20 \mu \mathrm{M}$ CHP treatments for $24 \mathrm{hrs}$ as compared to untreated cells. 
Normal human melanocytes (NHM)/ immortalized normal human melanocytes (PIG1) and immortalized melanocytes from vitiligo patient (PIG3V) were treated in a dose dependent manner with CHP (10$100 \mu \mathrm{M})$ and observed after $24 \mathrm{hrs}$ for viability. NHM showed significant decrease in viability (mean \pm SEM) upon: $90.94 \pm$ $1.50 \%$ at $10 \mu \mathrm{M}(p=0.049), 79.08 \pm 4.37 \%$ at $20 \mu \mathrm{M}(p=0.016), 76.40 \pm 5.81 \%$ at $40 \mu \mathrm{M}$ $(p=0.022), \quad 66.10 \pm 2.48 \%$ at $60 \mu \mathrm{M}$ $(p=0.0009), \quad 62.96 \pm 6.95 \%$ at $80 \mu \mathrm{M}$ $(p=0.008)$ and $53.83 \pm 7.09 \%$ at $100 \mu \mathrm{M}$ $(p=0.004)$ CHP treatment for $24 \mathrm{hrs}$ as compared to untreated NHM (Figure 1A). PIG1 showed significant decrease in viability (mean \pm SEM) upon: $85.77 \pm$ $1.60 \%$ at $10 \mu \mathrm{M}(p=0.036), 76.78 \pm 3.43 \%$ at $20 \mu \mathrm{M}(p=0.014), 72.17 \pm 1.90 \%$ at $40 \mu \mathrm{M}$ $(p=0.006), \quad 57.71 \pm 1.03 \%$ at $60 \mu \mathrm{M}$ $(p=0.002), \quad 52.74 \pm 6.93 \%$ at $80 \mu \mathrm{M}$ $(p=0.005)$ and $53.60 \pm 8.23 \%$ at $100 \mu \mathrm{M}$ $(p=0.008)$ CHP treatment for $24 \mathrm{hrs}$ as compared to untreated cells (Figure 1B). PIG3V also showed significant decrease in viability (mean \pm SEM) upon: $78.16 \pm$ $3.27 \%$ at $10 \mu \mathrm{M}(p=0.008), 56.63 \pm 2.32 \%$ at $20 \mu \mathrm{M} \quad(p=0.0003), 55.44 \pm 3.57 \%$ at $40 \mu \mathrm{M}(p=0.0006), 57.23 \pm 2.54 \%$ at $60 \mu \mathrm{M}$ $(p=0.0004), \quad 53.80 \pm 3.35 \%$ at $80 \mu \mathrm{M}$ $(p=0.0005)$ and $47.71 \pm 3.54 \%$ at $100 \mu \mathrm{M}$ $(p=0.0002)$ CHP treatment for $24 \mathrm{hrs}$ as compared to untreated cells (Figure 1C). NHM and PIG1 cells showed similar susceptibility to $\mathrm{H}_{2} \mathrm{O}_{2}$ at all concentrations, whereas PIG3V cells showed more vulnerability to $\mathrm{H}_{2} \mathrm{O}_{2}$ upto $20 \mu \mathrm{M}$ and exhibited around $50 \%$ cell death at all higher concentrations (Figure $1 \& 2$ )

\subsection{Gene expression profile of Melanocytes under normal condition}

Expression of anti-oxidant genes CAT, GPX1, G6PD and PRDX3; stress related genes HSP60, HSP70, SERPI, SIRTI and POLH; and melanocyte specific genes MITF, TYR, TYRP1, TRPM1, EDN1 and $L A M P 1$ in untreated NHM, PIG1 and PIG3V were monitored (Figure 3). However, no significant difference was observed in the expression of CAT, GPX1, $G 6 P D$ and $P R D X 3$ between NHM and PIG1 $(p=0.976, \quad p=0.7458, \quad p=0.128, \quad p=0.983$ respectively; Figure 2). Further, no difference was observed in the expression of CAT, GPX1, G6PD and PRDX3 between NHM and PIG3V $(p=0.318, p=0.867$, $p=0.714$ and $p=0.664$ respectively). Also, no significant difference in the expression of CAT, GPX1, G6PD and PRDX3 was observed between PIG1 and PIG3V $(p=0.217, p=0.883, p=0.070$ and $p=0.666$ respectively). Significantly higher expression of HSP7O and SERPI was observed in PIG3V cells as compared to PIG1 ( $p=0.015$ and $p=0.049$ respectively; Figure 3). However, there was no difference observed for HSP70 and SERP1 expression between NHM and PIG3V $(p=0.095$ and $p=0.447$ respectively). Also, significant difference was not observed in the expression of HSP60, SIRT1 and POLH between NHM and PIG3V ( $p=0.914$, $p=0.312$ and $p=0.287$ respectively). No significant difference was observed in HSP60, HSP70, SERP1, SIRT1 and POLH expression was observed between PIG1 and NHM $\quad(p=0.400, \quad p=0.091, \quad p=0.054$, $p=0.875$ and $p=0.217$ ). Moreover, expression of HSP60, SIRT1 and POLH was not significantly different between PIG1 and PIG3V cells $(p=0.355, p=0.355, p=0.951)$. TYR, TRPMI and EZR expression was significantly decreased in PIG3V as compared to NHM ( $p=0.031, p=0.012$ and $p=0.022$ respectively). Though, no change was observed in MITF, TYRP1, EDN1 and $L A M P 1$ expression in PIG3V and NHM $(p=0.155, p=0.134, p=0.647$ and $p=0.151$ respectively). Further, no difference was observed in the expression of MITF, TYRP1, TRPM1, EDN1, EZR and LAMP1 between PIG1 and NHM $(p=0.197, \quad p=0.405$, $p=0.986, p=0.968, p=0.331, p=0.692$ and $p=0.685$ respectively). Also, there was no difference observed in the expression of MITF, TYRP1, TRPM1, EDN1, EZR and $L A M P 1$ between PIG3V and PIG1 $(p=0.725, \quad p=0.179, \quad p=0.216, \quad p=0.022$, 
$p=0.564, \quad p=0.125$ and $\quad p=0.273$ respectively).

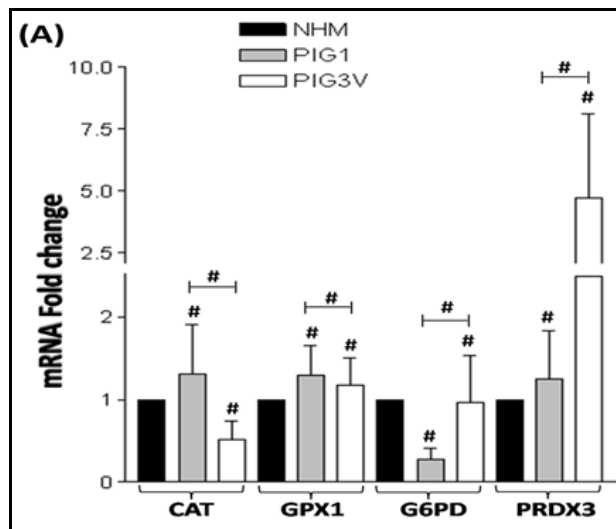

(B)

(C)
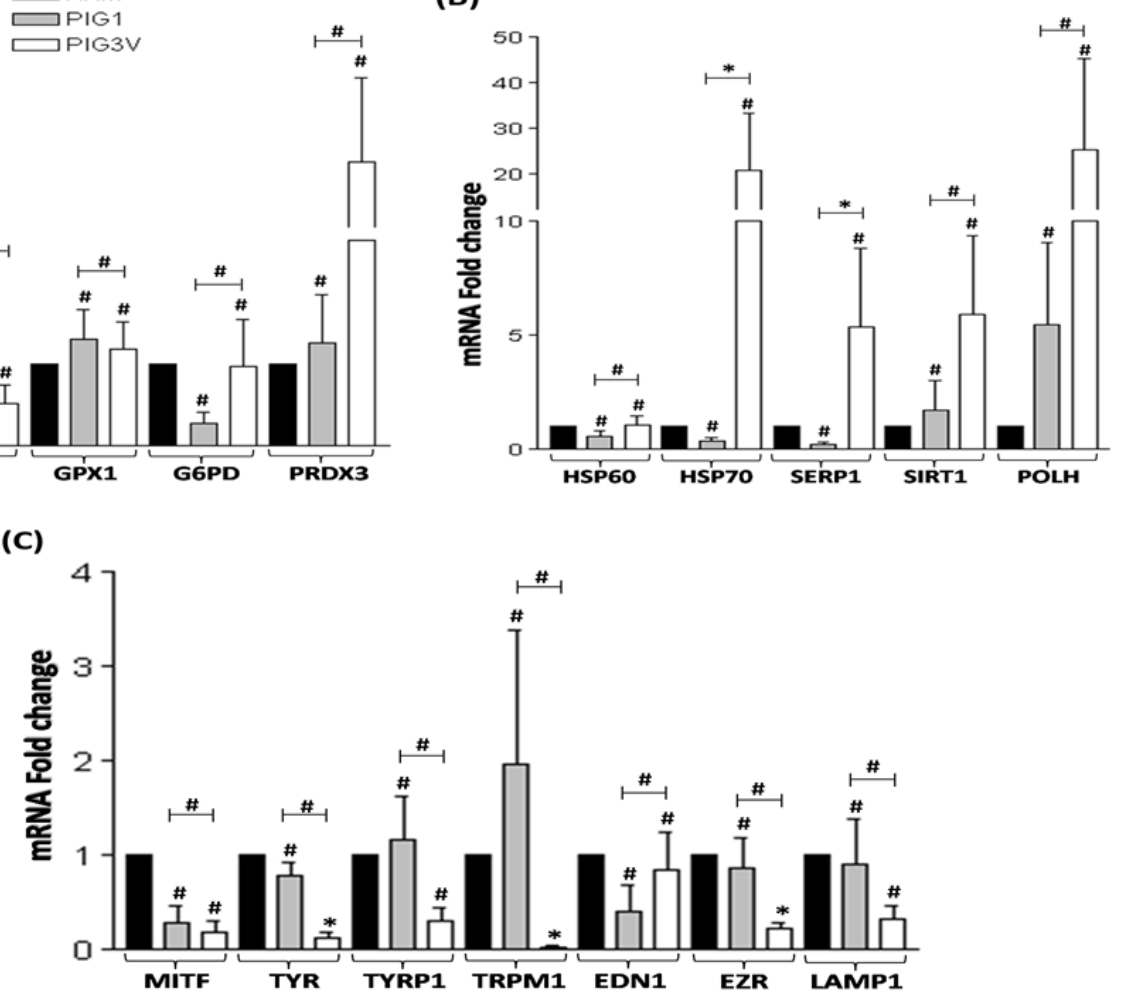

Figure 3. Gene expression profiles of NHM, PIG1 and PIG3V cells under normal condition. (A) Anti-oxidant genes: There was no difference in expression of CAT, GPX1, G6PD and PRDX3 among melanocytes. (B) Stress related genes: PIG3V showed higher expression of HSP70 and SERP1 as compared to PIG1. There was no difference in expression of HSP60, SIRT1 and POLH among melanocytes. (C)Melanocyte specific genes: PIG3V showed lower expression of TYR, TRPM1 and EZR as compared to NHM. There was no difference in expression of MITF, TYRP $1, E D N 1$ and LAMP1 among melanocytes. $\left[{ }^{*} p<0.05\right.$; ${ }^{*} p>0.05$ or non-significant]

\subsection{Gene expression profile of melanocytes under CHP induced oxidative stress}

NHM, PIG1 and PIG3V were treated with CHP $(10 \mu \mathrm{M} \& 20 \mu \mathrm{M})$ (Figure 2) and transcript levels of anti-oxidant genes, stress related genes and genes related to melanocytes were investigated after $24 \mathrm{hrs}$.

\subsection{1. mRNA expression levels at $10 \mu \mathrm{M}$ CHP}

PIG3V cells indicated markedly reduced $C A T$ expression as compared to NHM $(p=0.012)$ and increased PRDX3 expression as compared to PIG1 $(p=0.039)$. Although, there was no difference in $C A T$, GPX1, G6PD and PRDX3 expression among NHM and PIG1 cells $(p=0.071$, $p=0.244, \quad p=0.062 \quad$ and $\quad p=0.808$ respectively; Figure 4A). No significant difference in GPX1, G6PD and PRDX3 expression was observed between PIG3V and NHM ( $p=0.703, p=0.923$ and $p=0.427$ respectively). Also, no significant change in $C A T, G P X 1$ and $G 6 P D$ expression between PIG1 and PIG3V $(p=0.654, p=0.750$ and $p=0.128$ ).

PIG3V exhibited a significantly increase in $H S P 70$ expression as compared to NHM ( $p=0.023)$, and higher expression of HSP7O, SERPI and POLH in comparison to PIG1 ( $p=0.008, p=0.043$ and $p=0.043$ respectively; Figure 4B). However, there was no difference in HSP60, HSP70, SERPI, SIRTI and POLH expression between PIG1 and NHM $(p=0.579$, $p=0.636, p=0.124, p=0.534$ and $p=0.114$ respectively). In addition, no difference in HSP6O, SERPI, SIRTI and POLH expression was between PIG3V and NHM $(p=0.969, p=0.476, p=0.352$ and $p=0.356$ respectively). Moreover, the results suggested no difference in HSP6O and SIRTI expression between PIG1 and PIG3V 
$(p=0.361$, and $p=0.888)$. The PIG3V shown significantly decreased MITF, TYR, TRPMI, $E D N 1$ and EZR expression as compared to NHM $\quad(p=0.017, \quad p=0.015, \quad p=0.0003$, $p=0.014$ and $p=0.037$ respectively; Figure 4C). Also, we observed that MITF, TYR, TRPM1, EZR and LAMP1 expression was significantly decreased in PIG3V as compared to PIG1 upon CHP treatment ( $p=0.039, p=0.007, p<0.0001, p=0.009$ and $p=0.008$ respectively). However, there was no difference in MITF, TYR, TYRP1,
TRPM1, EDN1 and LAMPI expression between PIG1 and NHM $(p=0.638$, $p=0.771, \quad p=0.670, \quad p=0.139, \quad p=0.433$, $p=0.524$ and $p=0.661$ respectively). Further, no difference was observed in TYRP1 and LAMP1 expression between PIG3V and NHM ( $p=0.772$ and $p=0.145$ respectively). Also, there was no difference observed in TYRPI and EDN1 expression between PIG3V and PIG1 $(p=0.589$ and $p=0.915$ respectively).
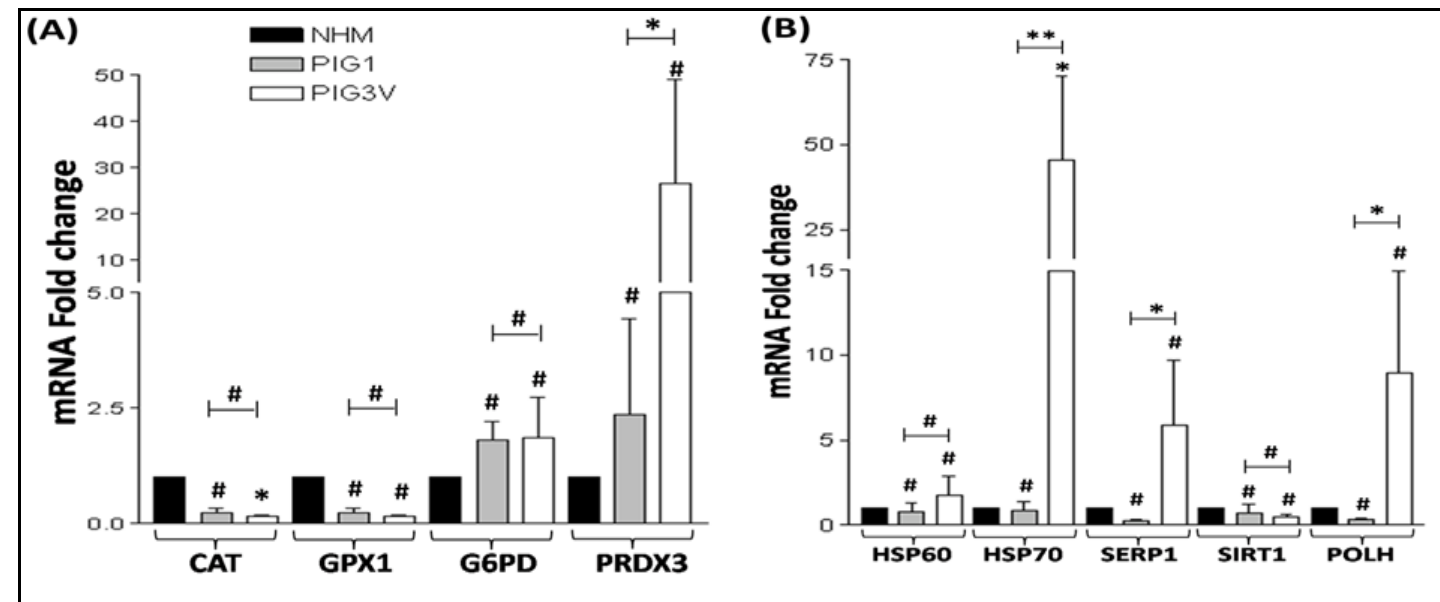

(C)

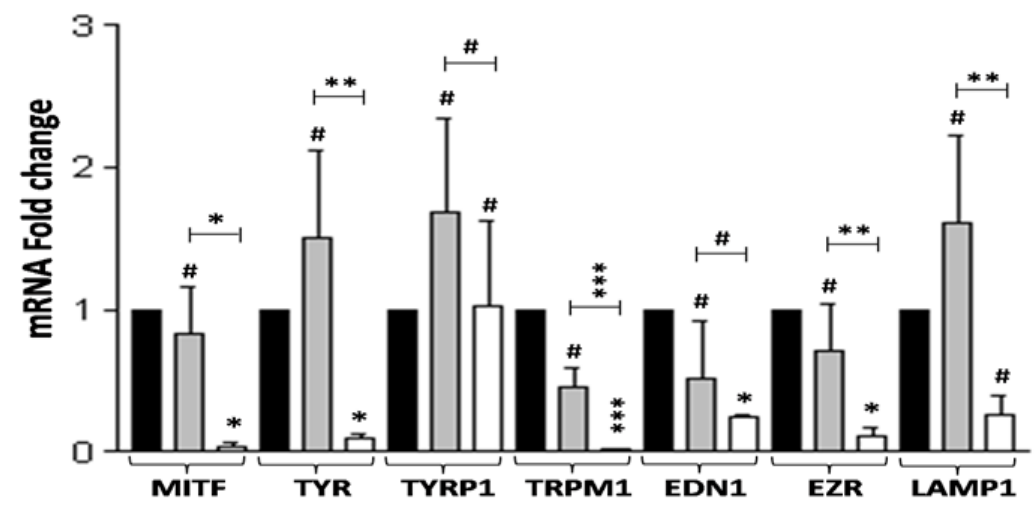

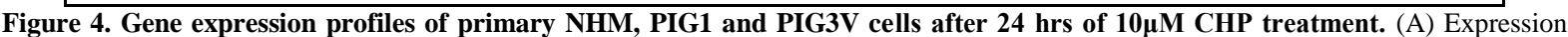
profile of anti-oxidant genes (B) Expression profile of stress related genes (C) Expression profile of melanocyte specific genes. [ ${ }^{*} p<0.05$; ${ }^{* * *} p<0.01 ;{ }^{* * * *} p<0.001 ;{ }^{\#} p>0.05$ or non-significant]

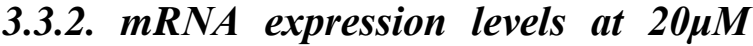 CHP}

PIG3V and PIG1 showed significantly decreased $C A T$ expression as compared to NHM $(p=0.019$ and $p=0.033$ respectively; Figure 5A). PIG3V showed an increased $P R D X 3$ expression in comparison to NHM and PIG1 $(p=0.005$ and $p=0.003$ respectively). No significant difference in $G P X 1, \quad G 6 P D$ and $P R D X 3$ expression between NHM and PIG1 was observed $(p=0.088, \quad p=0.078$ and $p=0.683$ respectively). Further, no difference was observed in GPX1 and G6PD expression between PIG3V and NHM $(p=0.127$ and $p=0.746$ respectively). Also, we did not observe any significant difference in $C A T$, $G P X 1$ and $G 6 P D$ expression between PIG1 and PIG3V $(p=0.159, p=0.871$ and $p=0.488$ respectively). HSP70 expression was 
significantly increased in PIG3V as compared to NHM $(p=0.047)$ and augmented HSP70, SERPI and POLH expression in comparison to PIG1 $(p=0.001$, $p=0.044$ and $p=0.043$; Figure 5B). PIG1 also showed significantly increased $P O L H$ expression as compared to NHM $(p=0.039)$. However, there was no difference in HSP60, HSP70, SERPI and SIRT1 expression between PIG1 and NHM $(p=0.129$, $p=0.217, \quad p=0.067$ and $p=0.905$ respectively). No difference was observed in HSP60 and SIRT1 expression between PIG3V and NHM ( $p=0.395$ and $p=0.154$ respectively). Further, no difference was observed in HSP6O and SIRTI expression between PIG1 and PIG3V cells $(p=0.085$, and $p=0.505$ respectively). The PIG3V cells indicated a significant downregulation of $M I T F, T Y R, T R P M 1$ and EZR expression as compared to NHM $(p=0.021, p=0.0004$, $p=0.032$ and $p=0.009$ respectively; Figure 5C). Moreover, PIG3V indicated downregulation of TYR, TYRP1, TRPM1 and EZR expression as compared to PIG1 $(p=0.012, p=0.044, p=0.027$ and $p=0.021$ respectively). However, there was no difference in MITF, TYR, TYRP1, TRPMI, EDN1 and LAMP1 expression between PIG1 and NHM $(p=0.263, p=0.081$, $p=0.815, p=0.056, p=0.916$ and $p=0.613$ respectively). Additionally, no difference in TYRP1, EDN1 and LAMP1 expression was observed between PIG3V and NHM $(p=0.176, \quad p=0.210 \quad$ and $\quad p=0.139$ respectively). Also, there was no difference in MITF, EDN1 and LAMP1 expression between PIG3V and PIG1 $(p=0.158$, $p=0.482$ and $p=0.325$ respectively).
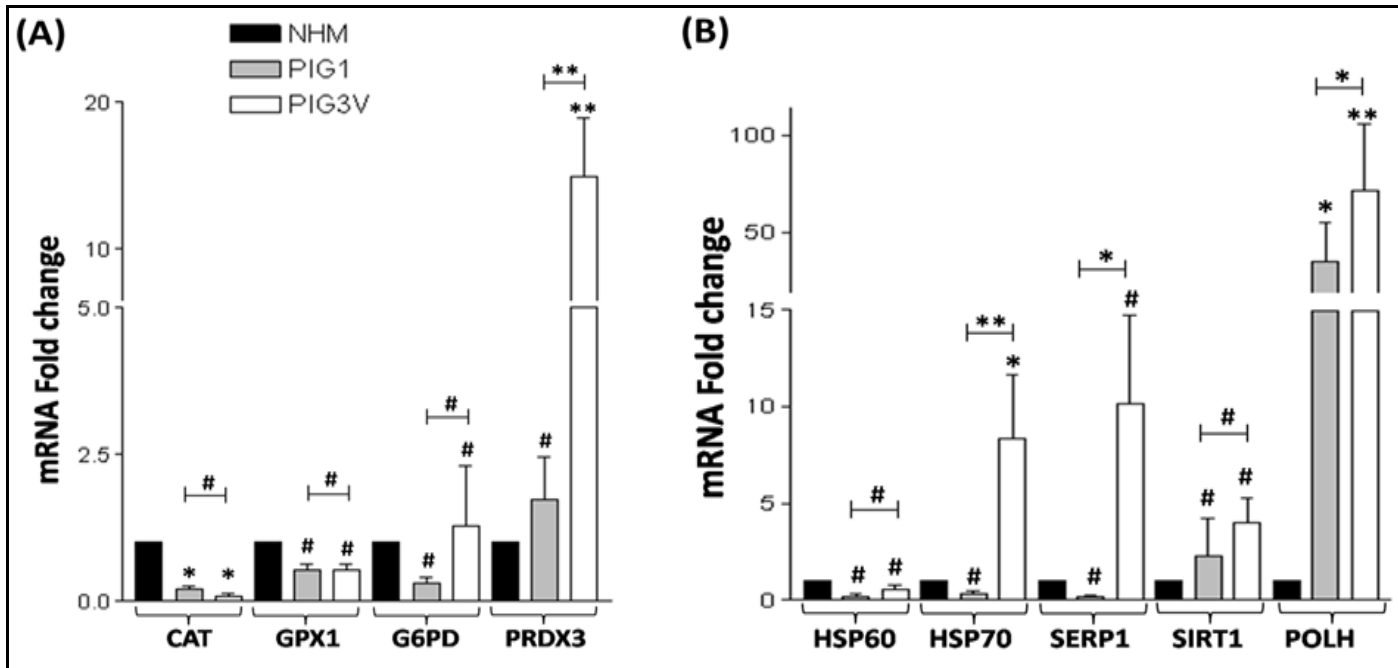

(C)

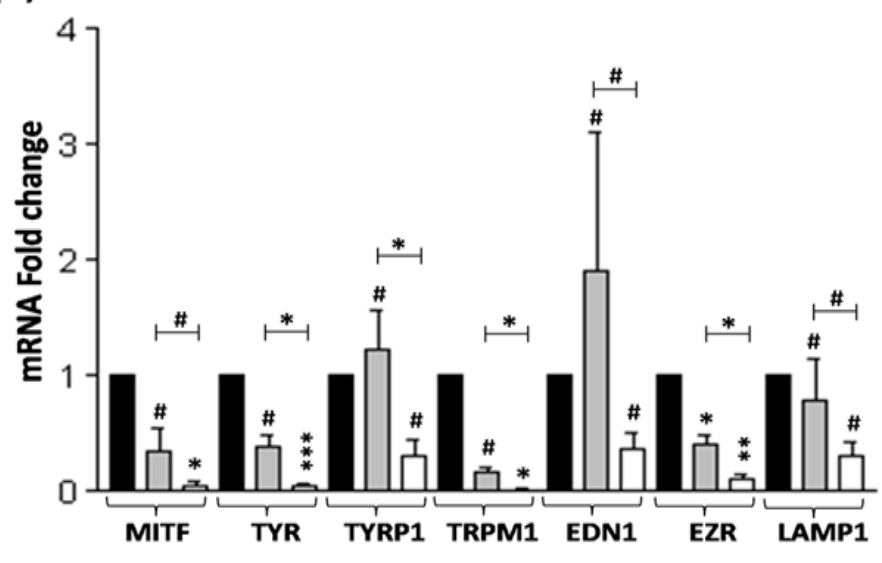

Figure 5. Gene expression profiles of primary NHM, PIG1 and PIG3V cells after $24 \mathrm{hrs}$ of $20 \mu \mathrm{M}$ CHP treatment. (A) Expression profile of anti-oxidant genes (B) Expression profile of stress related genes (C) Expression profile of melanocyte specific genes. [ ${ }^{*} p<0.05$; ${ }^{* *} p<0.01 ;{ }^{* * *} p<0.001 ;{ }^{\#} p>0.05$ or non-significant] 


\section{DISCUSSION}

Hampered (6R)-L-erythro 5,6,7,8 tetrahydrobiopterin $\left(6 \mathrm{BH}_{4}\right)$ regulation; impaired catecholamine production in addition to an augmented monoamine oxidase A (MOA) and low GPX activity are the among the major sources for epidermal $\mathrm{H}_{2} \mathrm{O}_{2}$ generation in vitiligo (Schallreuter et al. 1999). Over production of $\mathrm{H}_{2} \mathrm{O}_{2}$ may cause catalase inactivation and vacuolation in the epidermal melanocytes and keratinocytes. Interestingly, vitiligo melanocytes exhibited 'vacuolation' in vitro in which was reversible upon addition of catalase (Schallreuter et al. 1999).

Earlier, Maresca et al. have demonstrated that vitiligo melanocytes were susceptible to the toxic effect of CHP (Maresca et al. 1997). Similarly, in the present study PIG3V were found to be more sensitive to $\mathrm{CHP}$ in contrast to PIG1 and NHM (Figure 1). Further, PIG3V exhibited downregulation of CAT expression in comparison to NHM upon CHP exposure (Figures 2 and 3), which is in accordance with previous study (Maresca et al. 1997). Peroxiredoxins (PRDXs) act as free radical scavenger and are also involved in the degradation of $\mathrm{H}_{2} \mathrm{O}_{2}$ (Gourlay et al. 2003; Wood et al. 2003; Sue et al. 2005). Earlier, we have reported the up-regulated PRDX3 in skin and blood of vitiligo patients (Mansuri et al. 2016b). PRDX3 was found to elevated in PIG3V melanocytes as compared to NHM and/ PIG1 melanocytes (Figures 2 and 3), suggesting its protective role in vitiligo melanocytes.

Consequently, local and systemic high levels of $\mathrm{H}_{2} \mathrm{O}_{2}$ are able to alter the calcium homeostasis in melanocytes (Schallreuter et al. 2007). Schallreuter et al. have shown that cells from the lesional skin showed decreased $\mathrm{Ca}^{2+}$ uptake (Schallreuter-Wood et al. 1996). The present study suggests that TRPMI expression is decreased in PIG3V melanocytes (Figure 3). Moreover, PIG3V melanocytes showed significantly decreased expression of TRPM1 in response to CHP as compared to NHM and/ PIG1 (Figures 3 and 4), indicating its essential role in vitiligo pathogenesis.

Differential expression of stress proteins HSP60 and HSP70 is reported in the skin of vitiligo patients including our recent study (Thörneby-Andersson et al. 2000; Mosenson et al. 2012; Mansuri et al. 2016b). In the present study, PIG3V showed higher expression of $H S P 70$ in response to CHP induced oxidative stress (Figures 3 and 4) which is in accordance with the previous study where, exposure to 4-tertiary butyl phenol (4-TBP) enhanced the expression of HSP70 in melanocytes (Kroll et al. 2005). 4-TBP is reported to induce oxidative stress (O'Brien 1991; Thörneby-Andersson et al. 2000). Also, PIG3V showed a tendency to be more sensitive to 4-TBP as compared to PIG1 (Kroll et al. 2005). Recently, Sastry et $a l$., have reported significant upregulation of HSP70 expression in $\mathrm{H}_{2} \mathrm{O}_{2}$ treated PIG1 cells (Sastry et al. 2019). Asea et al., reported that HSP70 induced monocytes/macrophages showed secretion of cytokines such as IL-1, IL-6, and TNF- $\alpha$ (Asea et al. 2000). Also it has been shown that melanocytes can generate cytokines as well and elevated levels of TNF- $\alpha$ are reported (Krüger-Krasagakes et al. 1995)

SERP1 stabilizes membrane proteins during stress and facilitates subsequent glycosylation, which protects unfolded target proteins against degradation during ER stress (Yamaguchi et al. 1999). Whereas, EZR acts as a linker between the plasma membrane and cytoskeleton; and interacts with intercellular adhesion molecules 1 and 2 (Vaheri et al. 1997). Defective cell proliferation and adhesion mediated events were observed in mutant EZR (Y145F) expressing epithelial cells (Srivastava et al. 2005). SERP1 and EZR were found to be down-regulated in the lesional and non-lesional skin and blood of patients (Mansuri et al. 2016b). In contrast, PIG3V melanocytes exhibit higher levels of SERP1 and lower levels of EZR as compared to PIG1 and NHM respectively (Figure 3), indicating accumulation of unfolded proteins in vitiligo melanocytes. 
Additionally, PIG3V melanocytes showed increased SERPI expression as compared to NHM and/ PIG1 cells (Figures 3 and 4). However, EZR was down-regulated in PIG3V melanocytes in response to CHP as compared to NHM and/ PIG1 cells (Figure 4 \& 5). Previously, we have proposed that ER stress might be playing an important role in connecting oxidative stress and autoimmunity in vitiligo (Shoab Mansuri et al. 2014). This is further supported by decreased expression of EZR and increased expression of SERPI in vitiligo melanocytes.

Endothelin 1 (EDN1) is a paracrine growth factor synthesized by numerous cell types including keratinocytes, which interacts synergistically with $\alpha-\mathrm{MSH}$ and basic fibroblast growth factor that together affect melanocyte proliferation, migration, tyrosinase activity, melanogenesis, and dendrite formation (Hara et al. 1995; Tada et al. 1998). EDN1 also increases the expression and phosphorylation of MITF (Kadekaro et al. 2005). Manga et al. (Manga et al. 2006) have demonstrated that EDN1 caused an increased melanocyte susceptibility to 4-TBP and that MITF expression is reliant on the redox condition of cells (Jiménez-Cervantes et al. 2001). Previously, we showed that EDN1 was down-regulated in lesional skin and blood of vitiligo patients (Mansuri et al. 2016b). The present study showed significantly decreased expression of EDN1 in PIG3V as compared to NHM in response to $10 \mu \mathrm{M}$ CHP (Figure 4), suggesting an important role for EDN1 in the regulation of human melanocytes. Pathways involved in MITF regulation were found to be defective in vitiligo (Kitamura et al. 2004). Reduced MITF levels might lead to decreased expression of TYRP1 and related genes resulting in activation of apoptosis during oxidative stress (Manga et al. 2006). TYR and TYRP1 are expressed in melanocytes and mainly localized in melanosomes where they play key roles in promoting melanogenesis (Sturm and Duffy 2012). LAMP1 is a vesicular membrane glycoprotein of melanocytes (Zhou et al. 1993). TYR, TYRP1 and LAMP1 are expressed as a multi-protein complex and function together by stabilizing the enzymeprotein complex within the melanosome and prevent the premature death of melanocytes due to tyrosinase-mediated cytotoxicity (Ghanem and Fabrice 2011). Jimbow et al. have indicated that higher susceptibility of vitiligo melanocytes is concordant to the higher sensitivity for oxidative stress (ultraviolet B) (Jimbow et al. 2001), which may arise from abnormal synthesis, altered folding and maturation of nascent TYRP1 polypeptides along with decreased expression of TYRPI in vitiligo melanocytes was demonstrated (Luo et al. 1994). MITF stimulates melanin synthesis by regulating expression of melanogenic enzymes (TYR and TYRP1) and reduced expression of MITF and TYRP1 in melanocytes was observed under oxidative stress (Luo et al. 1994; Manga et al. 2006). Our previous study has shown decreased expression of $T Y R$, TYRP1, and LAMP1 in lesional and non-lesional skin (Mansuri et al. 2016b). In the present study, we found the downregulation of MITF, TYR, TYRP1, and $L A M P 1$ in PIG3V melanocytes as compared to NHM and/ PIG1 melanocytes in response to CHP (Figures 4 and 5). Interestingly, TYR expression was significantly downregulated in PIG1 melanocytes under oxidative stress condition (Sastry et al. 2019). Overall, these studies advocate the reduced mRNA expression of TYRPI in vitiligo melanocytes with abnormal processing of TYRP1 polypeptides, which may results in increased and abnormal antigen presentation of TYRP1 peptides on melanocyte membrane leading to autoimmune response via anti-TYRP1 antibodies and/ or $\mathrm{T}$ cell attack on melanocytes in patients with vitiligo (Jiménez-Cervantes et al. 2001; Jimbow et al. 2001; Manga et al. 2006).

POLH is a member of nucleotide excision repair family genes, which encodes Pol, a specialized polymerase that is able to bypass UV lesions (Yu et al. 2012). When POLH is defective, UV-induced DNA 
lesions are replicated by a more error-prone polymerase that produces more mutations (Flanagan et al. 2007). UV-induced DNA damage in melanocytes is more effectively prevented in the darker skin due to melanin (Lee et al. 2013). It has been reported that stimulation of melanogenesis in human melanocytes increased UVA-induced DNA damage (Denat et al. 2014). In conditions of vitiligo, melanocytes are under oxidative stress UV-induced DNA damage and activation of POLH is obvious. Our previous study has shown the upregulated expression of $P O L H$ in the lesional and nonlesional skin as well as in the blood of patients with stable vitiligo, indicating its protective role (Mansuri et al. 2016b). In addition, PIG3V melanocytes showed significantly increased expression of POLH in response to CHP (Figures 4 and 5).

Understanding the mechanism of $\mathrm{H}_{2} \mathrm{O}_{2}$ induced melanocyte death could elucidate the pathology underlying vitiligo in general. Melanocyte vulnerability to oxidative stress plays a vital role in the vitiligo pathogenesis. Here we have indicated that CHP promotes oxidative stress in melanocytes, and that melanocytes derived from vitiligo patients are more vulnerable to $\mathrm{CHP}$ induced oxidative stress as compared to normal melanocytes. We, for the first time, have demonstrated that CHP altered the expression of key genes involved in melanocyte development, oxidative stress and other cellular stress responses, making them susceptible for destruction.

\section{CONCLUSION}

In conclusion, vitiligo might result from an insufficient response of melanocytes to $\mathrm{H}_{2} \mathrm{O}_{2}$ induced oxidative stress. These findings will pave the way towards the development of novel therapeutic approaches for the treatment of vitiligo.

\section{ACKNOWLEDGMENTS}

We sincerely thank all the skin sample donors for participating in the study.
We thank Dr. I. C. Le Poole for providing us the PIG1 and PIG3V cells. MSM and SDJ thank UGC, New Delhi for awarding SRF. MS thanks, CSIR, New Delhi for awarding SRF.

Funding: This work was supported by grants to RB from the Indian Council of Medical Research (ICMR), New Delhi, "BMS/Adhoc/122/11-2012", Department of Biotechnology (DBT), New Delhi, "BT/PR9024/MED/12/332/2007" and Gujarat State Biotechnology Mission (GSBTM), Gandhinagar, Gujarat, "GSBTM/MD/PROJECTS/SSA/453/20102011".

Conflicts of interest: The authors declare no conflict of interest.

\section{REFERENCES}

1. Agrawal D, Shajil EM, Marfatia YS, and Begum R 2004 Pigment Cell Res. https://doi.org/10.1111/j.16000749.2004.00149.x

2. Asea A, Kabingu E, Stevenson MA, and Calderwood SK 2000 Cell Stress Chaperones https://doi.org/10.1379/14661268(2000)005<0425:HPBAPN>2.0.CO;2

3. Beazley WD, Gaze D, Panske A, Panzig E, and Schallreuter KU 1999 Br. J. Dermatol. https://doi.org/10.1046/j.13652133.1999.02980.x

4. Bickers DR and Athar M 2006 J. Invest. Dermatol. https://doi.org/10.1038/sj.jid.5700340

5. Bogeski I, Kilch T, and Niemeyer BA 2012 J. Physiol.

6. Briganti S and Picardo M 2003 J. Eur. Acad. Dermatology Venereol.

7. Calabrese V, Scapagnini G, Catalano C, Bates TE, Geraci D, Pennisi G, and Giuffrida AMS 2001 Int. J. Tissue React. 23 127-35

8. Czajkowski R, Placek W, Drewa T, Kowaliszyn B, Sir J, and Weiss W 2007 Dermatologic https://doi.org/10.1111/j.1524 4725.2007.33216.x

9. Denat L, Kadekaro AL, Marrot L, Leachman SA, and Abdel-Malek ZA 2014 J. Invest. Dermatol. 
10. Devi S, Kedlaya R, Maddodi N, Bhat KMR, Weber CS, Valdivia H, and Setaluri V 2009 Am. J. Physiol. - Cell Physiol. https://doi.org/10.1152/ajpcell.00092.2009

11. Em S, Laddha NC, Chatterjee S, Gani AR, Malek RA, Shah BJ, and Begum R 2007 Pigment cell Res. 20 405-7

12. Fang D and Setaluri V 1999 Biochem. Biophys. Res. Commun. https://doi.org/10.1006/bbrc.1999.0400

13. Flanagan AM, Rafferty G, O'Neill A, Rynne L, Kelly J, McCann J, and Carty MP 2007 Int. J. Mol. Med. https://doi.org/10.3892/ijmm.19.4.589

14. Fuchs E and Raghavan S 2002 Nat. Rev. Genet. 3 199-209

15. Gaur A, Jewell DA, Liang Y, Ridzon D, Moore JH, Chen C, Ambros VR, and Israel MA $2007 \quad$ Cancer Res. https://doi.org/10.1158/0008-5472.CAN-062698

16. Ghanem G and Fabrice J 2011 Mol. Oncol. $5150-5$

17. Gourlay LJ, Bhella D, Kelly SM, Price NC, and Lindsay JG 2003 J. Biol. Chem. https://doi.org/10.1074/jbc.M303862200

18. Hara M, Yaar M, and Gilchrest BA 1995 J. Invest. Dermatol. https://doi.org/10.1111/15231747.ep12325522

19. Hunter JJ et al. 1998 Genomics https://doi.org/10.1006/geno.1998.5549

20. Im S, Seung Kyung Hann, Park YK, and Hyung Il Kim 1993 Yonsei Med. J. https://doi.org/10.3349/ymj.1992.33.4.344

21. Jimbow K, Chen H, Park J-S, and Thomas PD 2001 Br. J. Dermatol. 144 55-65

22. Jiménez-Cervantes C, Martínez-Esparza M, Pérez C, Daum N, Solano F, and GarcíaBorrón JC 2001 J. Cell Sci.

23. Kadekaro AL et al. 2005 Cancer Res. https://doi.org/10.1158/0008-5472.CAN-044535

24. Kitamura R, Tsukamoto K, Harada K, Shimizu A, Shimada S, Kobayashi T, and Imokawa G 2004 J. Pathol. A J. Pathol. Soc. Gt. Britain Irel. 202 463-75

25. Koca R, Armutcu F, Altinyazar HC, and Gürel A 2004 Clin. Exp. Dermatol. https://doi.org/10.1111/j.13652230.2004.01524.x

26. Kroll TM, Bommiasamy H, Boissy RE, Hernandez C, Nickoloff BJ, Mestril R, and Poole IC Le 2005 J. Invest. Dermatol. 124 798-806
27. Krüger-Krasagakes S, Krasagakis K, Garbe C, and Diamantstein T 1995 Production of cytokines by human melanoma cells and melanocytes; in: Skin Cancer: Basic Science, Clinical Research and Treatment (Springer) pp 155-68

28. Laddha NC et al. 2014 Exp. Dermatol. 23 352-3

29. Laddha NC, Dwivedi M, Gani AR, Shajil EM, and Begum R 2013 Free Radic. Biol. Med.

https://doi.org/10.1016/j.freeradbiomed.201 3.08 .189

30. Lee $\mathrm{CH}, \mathrm{Wu} \mathrm{SB}$, Hong $\mathrm{CH}, \mathrm{Yu} \mathrm{HS}$, and Wei YH 2013 Int. J. Mol. Sci. https://doi.org/10.3390/ijms14036414

31. Levy C et al. 2010 Mol. Cell https://doi.org/10.1016/j.molcel.2010.11.02 0

32. Luo D, Chen H, and Jimbow K 1994 Exp. Cell Res. https://doi.org/10.1006/excr.1994.1195

33. Manga P, Sheyn D, Yang F, Sarangarajan R, and Boissy RE 2006 Am. J. Pathol. https://doi.org/10.2353/ajpath.2006.050769

34. Mansuri MS, Laddha NC, Dwivedi M, Patel D, Alex T, Singh M, Singh DD, and Begum R 2016a Exp. Dermatol.

35. Mansuri MS, Singh M, and Begum R 2016b J. Dermatol. Sci. 84 50-8

36. Maresca V, Roccella M, Roccella F, Camera E, Porto G Del, Passi S, Grammatico P, and Picardo M 1997 J. Invest. Dermatol. https://doi.org/10.1111/15231747.ep12335801

37. Mosenson JA, Zloza A, Klarquist J, Barfuss AJ, Guevara-Patino JA, and Poole IC Le 2012 Pigment Cell Melanoma Res. https://doi.org/10.1111/j.1755148X.2011.00916.x

38. O’Brien PJ 1991 Chem. Biol. Interact.

39. Passi S, Grandinetti M, Maggio F, Stancato A, and Luca C De 1998 Pigment Cell Res. https://doi.org/10.1111/j.16000749.1998.tb00714.x

40. Poole IC Le et al. 2000 Vitr. Cell. Dev. Biol. - Anim. https://doi.org/10.1290/10712690(2000)036<0309:paihvm>2.0.co;2

41. Poole C Le and Boissy RE 1997 Semin. Cutan. Med. Surg.

42. Proksch E, Brandner JM, and Jensen J 2008 Exp. Dermatol. 17 1063-72

43. Renis M, Cardile V, Grasso S, Palumbo M, and Scifo C 2003 Life Sci. 74 757-69 
44. Sastry KS, Naeem H, Mokrab Y, and Chouchane AI 2019 Oxid. Med. Cell. Longev. https://doi.org/10.1155/2019/2841814

45. Schallreuter-Wood KU, Pittelkow MR, and Swanson NN 1996 Arch. Dermatol. Res. https://doi.org/10.1007/BF02505036

46. Schallreuter KU et al. 1999 In vivo and in vitro evidence for hydrogen peroxide $(\mathrm{H} 2 \mathrm{O} 2)$ accumulation in the epidermis of patients with vitiligo and its successful removal by a UVB-activated pseudocatalase; in: Journal of Investigative Dermatology Symposium Proceedings

47. Schallreuter KU, Gibbons NCJ, Zothner C, Abou Elloof MM, and Wood JM 2007 Biochem. Biophys. Res. Commun. https://doi.org/10.1016/j.bbrc.2007.05.218

48. Shajil EM and Begum R 2006 Pigment Cell Res.

49. Shoab Mansuri M et al. 2014 J. Pigment. Disord. 01 https://doi.org/10.4172/23760427.1000123

50. Spritz RA 2008 The genetics of generalized vitiligo; in: Dermatologic Immunity (Karger Publishers) pp 244-57

51. Srivastava J, Elliott BE, Louvard D, and Arpin M 2005 Mol. Biol. Cell https://doi.org/10.1091/mbc.E04-08-0721

52. Sturm RA and Duffy DL 2012 Genome Biol.

53. Sue GR, Ho ZC, and Kim K 2005 Free Radic. Biol. Med.
54. Tada A, Suzuki I, Im S, Davis MB, Cornelius J, Babcock G, Nordlund JJ, and Abdel-Malek ZA 1998 Cell Growth Differ.

55. Thörneby-Andersson K, Sterner $\mathrm{O}$, and Hansson C 2000 Pigment Cell Res. https://doi.org/10.1034/j.16000749.2000.130107.x

56. Vaheri A et al. 1997 Curr. Opin. Cell Biol. 9 659-66

57. Widlund HR and Fisher DE 2003 Oncogene

58. Wood ZA, Poole LB, and Karplus PA 2003 Science (80-. https://doi.org/10.1126/science.1080405

59. Yamaguchi A, Hori O, Stern DM, Hartmann E, Ogawa S, and Tohyama M 1999 J. Cell Biol. 147 1195-204

60. Yu M, Bell RH, Ho MM, Leung G, Haegert A, Carr N, Shapiro J, and McElwee KJ 2012 PLoS

One https://doi.org/10.1371/journal.pone.003418 5

61. Zhou BK, Boissy RE, Pifko-Hirst S, Moran DJ, and Orlow SJ 1993 J. Invest. Dermatol. https://doi.org/10.1111/15231747.ep12462775

How to cite this article: Mansuri MS, Singh M, Jadeja SD et.al. An in vitro study elucidating the effect of oxidative stress on melanocytes. International Journal of Research and Review. 2021; 8(2): 142-154. 